\title{
POLIÍTICAS DO EXTRAORDINÁRIO - EXCEÇÃO, DITADURA COMISSARIAL E DITADURA SOBERANA: LÓGICAS DE TRANSFORMAÇÃO EM SCHMITT E BADIOU
}

\author{
Politics of the extraordinaire - Exception, commissarial dictatorship and sovereign \\ dictatorship: logics of transformation in Schmitt and Badiou
}

Jonathan Arriola Socías*

Resumo: O objetivo deste trabalho é analisar as lógicas de transformação nas obras de Alain Badiou e Carl Schmitt. Para fazê-lo, em primeiro lugar exploraremos as numerosas semelhanças que existem entre a perspectiva fenômeno-lógica de Badiou e a filosofia política de Schmitt. Principalmente, concentrar-nos-emos nas categorias de exceção e acontecimento, assim como na concepção de sujeito dos autores, dado que, segundo ambos os filósofos, é justamente a interação entre esses elementos o que permite a possibilidade de emergência da transformação em seus respectivos sistemas. $\mathrm{O}$ artigo começa investigando qual é a origem dessas semelhanças, assinando que a mesma se encontra na forte herança romântica presente nos dois autores. Seguiremos com uma análise dos conceitos de exceção (Schmitt) e acontecimento (Badiou), demarcando cada um dos pontos que os mesmos têm em comum. Na terceira parte, o objetivo geral será de ver a filosofia política de Schmitt através das lentes da fenômeno-lógica de Badiou. Para isso, abordaremos a importante distinção conceptual que faz o filósofo alemão entre a ditadura comissarial e a soberana e a distinta concepção de sujeito que elas pressupõem. $\mathrm{Na}$ parte final do trabalho, aduziremos que essa distinção tem uma correspondência com as categorias fenômeno-lógicas de Badiou. Com efeito, segundo nossa opinião, as noções de exceção e de extraordinário de Schmitt fazem lembrar as noções de singularité faible e de singularité forte de Badiou e, por sua vez, as figuras de ditador comissarial e soberano às de sujet reatif, sujet obscur e sujet fidèle.

Palavras-chave: Badiou. Schmitt. Acontecimento. Exceção. Ditadura. Sujeito. Transformação.

\begin{abstract}
The aim of this paper is to analyze the logic of transformation in the works of Alain Badiou and Carl Schmitt. In order to do so, we will explore the similarities that exist between the phenomeno-logic perspective of Badiou and the political philosophy of Schmitt. Above all, we will focus on the categories of exception and event as well as on the conception of the subject that both authors develop since it is precisely the interaction between those elements that which allows the possibility of transformation to emerge in their respective systems. The paper begins by investigating which are the origins of those parallelisms, arguing that they can be found in the strong romantic heritage that both authors share. Following, we will study the concepts of exception (Schmitt) and event (Badiou), underlining each of points they have the common. In the third part, the general objective is to see Schmitt's political philosophy through Badiou's phenomeno-logic lens. To do so, we will first approach Schmitt's notions of the exception and the extraordinaire as well as his famous distinction between the commissarial and sovereign dictatorships, emphasizing the different conceptions of the subject each one presupposes. In the final part, we will argue that such distinction has a correspondence with Badiou's phenomeno-logic categories. In effect, according to our view, Schmitt's notions of the exception and the extraordinaire strongly recall Badiou's notions of singularité faible and singularité forte and, in turn, the figures of commissarial and sovereign dictatorships those of sujet reatif, sujet obscur e o sujet fidèle.
\end{abstract}

Keywords: Badiou. Schmitt. Event. Exception. Dictatorship. Subject. Transformation.

* Mestrando em Filosofia Contemporânea pela Universidade da República em Montevidéu. Contato: jon.arriola@hotmal.com

\begin{tabular}{|c|c|l|l|l|l|}
\hline intuitio & $\begin{array}{c}\text { ISSN } \\
1983-4012\end{array}$ & Porto Alegre & Vol.7- $\mathrm{N}^{\mathrm{o}} .1$ & $\begin{array}{c}\text { Junho } \\
2014\end{array}$ & p.79-102 \\
\hline
\end{tabular}




\section{Acontecimento e exceção}

a) A origem romântica de uma semelhança

Está fora de dúvida que, ainda quando compartilham a intensa crítica ao liberalismo, Schmitt e Badiou encontram-se precisamente nas antípodas ideológicas. Com efeito, o primeiro representou a quintessência do pensamento conservador e nacionalista da primeira metade do século XX, tendo sido, além disso, colaborador, embora efêmero, do Regime Nacional-socialista. O segundo, ao contrário, foi, e ainda é, um ativo defensor do comunismo (maoísta) e se destaca como um dos autores mais brilhantes da esquerda filosófica contemporânea. Porém, existem entre seus programas filosóficos vários paralelismos que, como veremos neste texto, são especialmente identificáveis nos conceitos centrais dos autores. Referimo-nos, por um lado, aos conceitos de exceção (Schmitt) e de acontecimento (Badiou) e, por outro, à definição de sujeito que ambos os filósofos desenvolvem.

Parte dessas afinidades que assinalamos já foram percebidas por alguns autores, como bem mostra Wright no seu Event or Exception? (2008). Efetivamente, um dos primeiros a apontar as influências da obra de Schmitt na filosofia de Badiou foi Lyotard. De fato, ele "acusou" Badiou de ser o "novo Carl Schmitt", ao considerar que o filósofo do chamado "gesto platônico" apela a um ato tipicamente decisionista no momento crucial da nominação do acontecimento. Um recurso que, afirma Lyotard, faz lembrar a doutrina jurídica elaborada pelo filósofo alemão, nos princípios do século XX, mas que Badiou, por sinal, tentou negar rápida e impetuosamente ${ }^{1}$. Na mesma linha que Lyotard foram também alguns autores norte-americanos como Peter Hallward e Nina Power, no entanto eles se concentram, principalmente, em questões como a concepção de sujeito de Badiou e as teorias absolutistas da soberania, tal como Schmitt apresenta, no primeiro caso, e as várias coincidências que existem entre Badiou e Schmitt entorno à sua critica de Rousseau ${ }^{2}$, no segundo caso. É, precisamente, com base nisso que Wright assinala, e não sem razão, que o "espectro de Schmitt" tem perseguido o filósofo francês desde a publicação de L'être et l'événement (1988), um dos seus textos principais juntamente com a Logiques des Mondes (2006) ${ }^{3}$.

Em nossa opinião, existem varias razões histórico-filosóficas para justificar essas semelhanças. Primeiramente, tanto a filosofia de Schmitt quanto a de Badiou são originárias de épocas convulsionadas e de rápidas transformações. Assim, foram, salvo as distâncias do caso, a Primeira Guerra Mundial ${ }^{4}$ e a ascensão do Nacional-socialismo na Alemanha de Schmitt, por um lado, e o Maio

${ }^{1}$ Cf. BADIOU, Alain. Infinite Thought: Truth and the Return of Philosophy. Ed. Continuum: London. 2004, p.173.

${ }^{2}$ WRIGHT, Colin. Event or Exception: Disentangling Badiou from Schmitt, or, Towards a Politics of the Void. In: Theory and Event 11.2. 2008. p. 1.

${ }^{3}$ WRIGHT, Colin. Event or Exception: Disentangling Badiou from Schmitt, or, Towards a Politics of the Void. In: Theory and Event 11.2. 2008. p. 1.

${ }^{4} \mathrm{Na}$ introdução, feita por Georg Schwab, do livro Political Theology, o autor assinala que: "World War I was a decisive in forming Schmitt's conception of the state and, hence, of sovereignty". In: SCHMITT, Carl. Political

\begin{tabular}{|c|c|l|l|l|l|}
\hline intuitio & $\begin{array}{c}\text { ISSN } \\
1983-4012\end{array}$ & Porto Alegre & Vol.7- $\mathrm{N}^{\mathrm{o}} .1$ & $\begin{array}{c}\text { Junho } \\
2014\end{array}$ & p.79-102 \\
\hline
\end{tabular}


de 68 e suas díspares consequências no nível cultural e político na França de Badiou, por outro. Estes eventos, assim como a própria Revolução Francesa em seu momento, têm em comum que trouxeram ao centro da preocupação filosófica da época, o problema da singularidade, conceito crucial em Schmitt e Badiou. Mas, além do estatuto de singularidade, outro dos aspectos que os dois períodos compartilharam, de acordo, entre outros, com Rüdiger Safranski, ${ }^{5}$ foi o forte "espírito romântico" que os caracterizou.

Em termos cronológicos, o Romantismo teve seu auge bem antes do desenvolvimento da obra dos dois autores. Contudo, quando dizemos "espírito romântico", referimo-nos em particular a uma atitude que, embora originada certamente no século XIX, não obedece a fronteiras temporais, tendo múltiplas manifestações ao longo do século $\mathrm{XX}^{6}$. Essa atitude romântica influenciou igualmente os contextos históricos de Schmitt e Badiou ${ }^{7}$ e caracteriza-se essencialmente por exaltar o revolucionário, por ser idealista, mas, sobretudo, por apelar ao dionisíaco como refúgio no meio da preeminência geral do apolíneo em que está baseada a modernidade ${ }^{8}$. Segundo nossa interpretação, é precisamente esse espírito que se deixa entrever nas obras dos dois autores, sendo que constitui, digamos assim, o "tronco comum" que explica várias das similitudes que aprofundaremos ao longo desse trabalho.

Neste ponto, há que dizer que quando asseveramos que o "espírito romântico" percorre as obras de Schmitt e Badiou, somos plenamente conscientes de que seguramente os dois recusariam esse rótulo. Com efeito, sabemos que Schmitt dedica, in totum, seu Politische Romantik (1919) a criticar fortemente o Romantismo por considerá-lo um movimento, por assim dizer, "hipermoderno". Ou seja, excessivamente centrado em um indivíduo totalmente entregue a seu próprio narcisismo e a uma ingênua vontade estetizadora do mundo, incapaz de decidir ${ }^{9}$. Nos mesmos termos depreciativos,

Theology. Georg Schwab's Introduction. Ed. The University of Chicago Press. United States of America. 2005, p. XLI.

${ }^{5}$ SAFRANSKI, Rüdiger. Romantismo: uma questão alemã. Tradução: Rita Rios. Ed. Estação Liberdade. 2009.

${ }^{6}$ Para aprofundar, conferir o texto de LÖWY, Michael; SAYRE, Robert. Romanticism Against the Tide of Modernity. Ed. Duke University Press. Durham. London. 2001.

${ }^{7}$ Com efeito, Löwy e Sayre afirmam do seguinte modo: "A Romantic dimension was present in varying degrees in most of these movements, in the critiques addressed to modern industrial societies as well as in the utopian aims that inspired them.” In: LÖWY, Michael; SAYRE, Robert. Romanticism Against the Tide of Modernity. Ed. Duke University Press. Durham. London. 2001. p. 219. E continua: "The Romantic gust of May '68 is not limited, however, to negativity. It is also manifested in the feeling of a rediscovered human community, in the experience of the revolution as a festival, in the ironic and poetic slogans written on walls, in the appeal to collective imagination and creativity as apolitical imperative, and finally in the utopian notion of a society free of all alienation and reification." LÖWY, Michael; SAYRE, Robert. Romanticism Against the Tide of Modernity. Ed. Duke University Press. Durham. London. 2001. p. 220.

${ }^{8}$ Para uma boa resenha desse texto em português, conferir o artigo "Obra de Rüdiger Safranski analisa o romantismo alemão". In: Jornal do Brasil, de Haron Gamal. Nesse contexto, o autor destaca o que nós justamente assinalamos com respeito ao paralelismo entre a época de Schmitt e a de Badiou: "O autor [Rüdiger Safranski] discorre sobre os movimentos românticos existentes na história do Ocidente; agora, como atitudes de vida. Dentre estas posturas, aparecem reação a qualquer tipo de realismo; mobilizações nacionalistas que desencadearam a Primeira Guerra; peregrinação de grupos de jovens que ocorreu na Alemanha, nos anos 20, visando um modelo de vida baseado no dionisíaco; muitos anos depois, o Maio de 1968." Disponível em: http://www.jb.com.br/cultura/noticias/2010/07/02/obra-de-rudiger-safranski-analisa-o-romantismo-alemao/

${ }^{9}$ Com efeito, "Por su actitud individual frente al mundo, la fórmula romántica para Schmitt es el mundo como mera ocasión para el goce estético. Los románticos se entregan a la eterna poetización del mundo; cada momento

\begin{tabular}{|c|c|l|l|l|l|}
\hline intuitio & $\begin{array}{c}\text { ISSN } \\
1983-4012\end{array}$ & Porto Alegre & Vol.7- N $^{\circ} .1$ & $\begin{array}{c}\text { Junho } \\
2014\end{array}$ & p.79-102 \\
\hline
\end{tabular}


Schmitt refere-se também ao Romantismo no seu famoso Politische Theologie (1922), caracterizandoo, de modo bastante esquemático, como um movimento que só sabe "conversar sem fim" (ewige Gespräch $)^{10}$.

Por seu lado, Badiou, com a redução da ontologia à matemática, faz um grande tributo ao quase esquecido reductio scientiae ad mathematicam do século XVII. Ao mesmo tempo, esse tributo constitui um gesto de reafirmação, no longamente criticado programa do Esclarecimento, que, em vários sentidos, aprofundou e ampliou muitas das consequências da Filosofia racionalista do século anterior. Uma reafirmação, há que se dizer, contrária tanto ao Romantismo ${ }^{11}$ quanto à pósmodernidade, movimentos pouco acolhedores à proposta fortemente racionalista do Esclarecimento. De fato, na teoria dos conjuntos irredutíveis de Badiou avança um projeto de ontologia fundamental que, em contraste ao que Heidegger defende, dá predominância ao matema sobre o poema, o que, sem dúvida, despertaria as objeções de muitos românticos sempre dispostos a "romantizar" o mundo por meio da sublimação poética, como quis Novalis ${ }^{12}$.

No entanto, apesar da aparente rejeição ao Romantismo, explícita em Schmitt e implícita em Badiou, insistimos que é constatável na filosofia de ambos os autores aspectos tipicamente românticos, sobretudo, três, os quais são de vital importância na obra dos autores.

Em primeiro lugar, o romântico, tal como se pode encontrar em Schmitt e Badiou, tem uma inclinação por tudo aquilo que escapa da vocação totalizadora dos sistemas e excede os limites do conceito, do representável e do definido como "normal". Atrai-lhe, em geral, tudo aquilo que não se submete ao principio de identidade, isto é, o radicalmente "outro", a "alteridade", e, além disso, tem um especial apresso pelo que não se deixa decodificar racionalmente. Examinando o que está fora da norma, o romântico resgata, contra a razão auto-transparente do Esclarecimento, o abismo do vazio, a falta essencial e, com ela, a angústia, o horror vacui do nada e o mistério absoluto de essência indizível e inominável. O romântico é também um mestre em mostrar os profundos paradoxos que oculta a realidade. Assim sendo, assinala a precariedade e historicidade de toda ordem que pretenda ser eterna, vê com profunda ironia a ideia que do caos possa nascer o cosmos. Desse modo, replica o otimismo do Esclarecimento de que pode haver, por detrás da aparência harmoniosa das leis naturais, totalmente acessíveis pela razão humana, um princípio opaco, possivelmente não racional, talvez um

es una oportunidad para experimentar pasivamente las emociones. Por ello, el concepto de ocasionalismo subjetivado ayudaría a comprender la filosofía del romántico." ATTILI, Antonella. La crítica decisionista de Carl Schmitt a la democracia liberal. In: Signos filosóficos, n. 10, julio-diciembre, 2003, p. 138.

${ }^{10}$ É preciso apontar que esse suposto vício da "conversação" foi, precisamente, o que o filósofo alemão percebeu como corporificado no frustrado parlamentarismo liberal da República de Weimar que levou a uma crise política ímpar na Alemanha dos anos 30.

${ }^{11}$ Precisamente, "Badiou is also the contemporary thinker who, more rigorously and originally than anyone else, has proselytized for the overcoming of Romantic philosophy." CLEMENS, Justin. The Romanticism of Contemporary Theory: Institutions, Aesthetics, Nihilism. Ed. Ashgate Publishing, Ltd., Jan 1, 2003 - Literary Collections. p. 191.

${ }^{12}$ Lembre-se o fragmento do poema de Novalis que se tornou um verdadeiro manifesto do Romantismo: "Ao dar um sentido elevado ao comum, ao dar ao usual uma aparência misteriosa, ao conhecido a nobreza do desconhecido, ao fugaz uma aparência de eterno, assim é que eu os romantizo".

\begin{tabular}{|c|c|l|l|l|l|}
\hline intuitio & $\begin{array}{c}\text { ISSN } \\
1983-4012\end{array}$ & Porto Alegre & Vol.7- $\mathrm{N}^{\mathrm{o}} .1$ & $\begin{array}{c}\text { Junho } \\
2014\end{array}$ & p.79-102 \\
\hline
\end{tabular}


Deus absconditus ou até deliberadamente irracional, como salientava, entre outros, de Maistre, o grande mentor, junto a Cortes e Bonald, de Schmitt.

Por outro lado, e do mesmo modo, em lugar de indivíduos puramente racionais e entregues a um tipo de solipsismo asocial, conforme lhe recrimina o liberalismo, o romântico vê o todo orgânico, que articula, desde suas entranhas mesmas, aos diversos Völker, dotando-os de um caráter cultural, político e social único, ao qual Fichte e Hegel, na esteira de Herder, denominaram de Geist. Devemos salientar que esta idéia do Geist dos povos fundamentará o conceito de comunidade (Gemeinsachft), uma concepção que os românticos, como por exemplo, Schiller ${ }^{13}$, contrapuseram à ideia de sociedade (Gesellschaft). Essa distinção, por sua vez, é a que estará na base mesma da crítica que Schmitt fará ao liberalismo ${ }^{14}$.

Em segundo lugar, por detrás do "Universal" e do "Um", os românticos encontram o "Particular" e o "Múltiplo" e, conjuntamente, com sua irremediável inconsistência, a qual também encontraremos no núcleo da filosofia de Badiou, descobrem a unidade subjacente de todas as coisas. Nessa perspectiva, novamente, é fundamental a ideia romântica de todo orgânico desenvolvida, principalmente, por Schelling, e que brindará, digamos assim, o "contexto de descoberta", por exemplo, da teoria dos conjuntos do Cantor $^{15}$, a qual constitui a medula da filosofia de Badiou ${ }^{16}$.

Em terceiro lugar, nascido ele mesmo de uma singularidade histórica, a saber, da Revolução Francesa, o romântico não pode ter nada menos do que um gosto intrínseco pelo extraordinário, qualquer que seja sua forma. De fato, foi justamente assim que o Romantismo, reagindo contra a parcimônia racionalizadora do Esclarecimento, procedeu ao outorgar ou, em alguns casos, ao restaurar a dignidade filosófica àqueles tipos de categorias ${ }^{17}$ que sublinham a dimensão misteriosa da realidade, tanto objetiva quanto subjetiva, e que fundariam escolas inteiras de pensamento no século XX, tais como o existencialismo, o vitalismo ou a psicanálise, entre muitas outras. Conforme será exposto, todos esses conceitos fazem parte, mais ou menos explicitamente, do vocabulário de Schmitt e Badiou $^{18}$ e são especialmente reconhecíveis nas noções de exceção e acontecimento dos autores.

\footnotetext{
${ }^{13} \mathrm{O}$ texto onde Schiller desenvolve uma crítica a sociedade burguesa é Cartas Sobre a Educação Estética do Homem (1795).

${ }^{14}$ Como efeito, segundo Schmitt, a sociedade liberal, entendida como um conjunto de pessoas essencialmente separadas, é um ente basicamente apolítico. Só no âmbito da comunidade, isto é, onde os indivíduos estão essencialmente ligados por um conjunto de valores comuns, a política pode ter lugar e razão de ser.

${ }^{15}$ Com relação a isso, conferir: FERREIRÓS, José. Del neohumanismo al organicismo: Gauss, Cantor y la matemática pura. Universidad de Sevilla. 2003, pp. 165-184.

${ }^{16}$ Para uma análise mais aprofundada da relação entre o Romantismo e Badiou, conferir o Capitulo 8, de The Romanticism of Contemporary Theory: Institutions, Aesthetics, Nihilism (2003), de Justin Clemens.

${ }^{17}$ Algumas delas são os conceitos de sublime (Schiller), de sinistro (E.T.A. Hoffmann), de instante (Nietzsche), de numinoso (Rudolf Otto) e de milagroso (Rosenzweig).

${ }^{18}$ Justin Clemens expõe uma tese similar: "Badiou is also the contemporary thinker who, more rigorously and originally than anyone else, has proselytized for the overcoming of Romantic philosophy. His arguments to this end are often very strong, and evade many of the Romantic difficulties that I have been outlining; indeed, much of the force of Badiou's work depends on the distance that he takes from Romanticism. This chapter will therefore try to bring out the originality and strength of Badiou's work - if, finally, I will suggest that he, too, cannot altogether evade the return of central Romantic motifs." CLEMENS, Justin. The Romanticism of
}

\begin{tabular}{|c|c|l|l|l|l|}
\hline intuitio & $\begin{array}{c}\text { ISSN } \\
1983-4012\end{array}$ & Porto Alegre & Vol.7- N $^{\circ} .1$ & $\begin{array}{c}\text { Junho } \\
2014\end{array}$ & p.79-102 \\
\hline
\end{tabular}


O anterior pode ser explicado pelo fato de que, em última instância, e sendo mais concretos, o binômio exceção/acontecimento tem raízes profundas na noção de Ausnahme (exceção), formulada por Kierkergaard, a qual, junto ao Veemod (melancolia), e a pesar do próprio filósofo que criticava fortemente ao Romantismo, condensa paradoxalmente vários aspectos da cosmovisão romântica ${ }^{19}$. No caso de Schmitt, a herança é direita. De fato, é sabida a grande influência que exerceu o autor dinamarquês sobre ele, ao qual cita explicitamente em Politische Theologie, para dar conta precisamente da natureza peculiar da exceção ${ }^{20}$. No caso de Badiou, porém, a herança é indireta, pois foi principalmente através da obra de Heidegger, o último "grande romântico" segundo Hannah Arendt, e, pontualmente, do seu conceito de Ereignis ${ }^{21}$, que é possível perceber os ecos distantes ${ }^{22}$ da Ausnahme, de Kierkergaard, no conceito de événement do filósofo francês.

Dado esse pano de fundo comum dos dois autores, poderíamos dizer, parafraseando o próprio Badiou, que do mesmo modo que há um momento alemão na Filosofia Francesa, há um momento especificamente romântico na sua filosofia e na de Schmitt.

\section{b) Acontecimento e exceção: afinidades e tensões}

Como adiantamos previamente, entre acontecimento e exceção, de Schmitt, existem vários pontos em comum que trabalharemos, brevemente, no que segue.

Em primeiro lugar, ambos os conceitos fazem referência a uma situação de singularidade dentro de um sistema, que se caracteriza, sobretudo, por ser incomensurável em relação aos parâmetros normais estabelecidos por esse sistema ${ }^{23}$. Podemos dizer que a incomensurabilidade desse tipo de situação deriva de sua natureza essencialmente rupturista. Com efeito, o acontecimento e a exceção são por definição o novo, isto é, uma alteridade que emerge de forma totalmente inesperada e que vem a interromper a continuidade natural de um determinado regime, seja este um estado de

Contemporary Theory: Institutions, Aesthetics, Nihilism. Ed. Ashgate Publishing, Ltd., Jan 1, 2003 - Literary Collections. p. 191.

${ }^{19}$ Sobre o "Romantismo" de Kierkegaard, conferir: Romantic Melancholy in Chateaubriand and Kierkegaard (1956), de Ronald Grimsley. Nesta mesma linha, segue María Binetti em El romanticismo de la angustia: de Kierkegaard a Heidegger y Lacan.

${ }^{20}$ Concretamente, "The exception [diz Schmitt] is more interesting than the rule. The rule proves nothing, the exception proves everything..." SCHMITT, Carl. Political Theology. The University of Chicago Press. United States of America. 2005. p. 15. Pouco depois, Schmitt cita Kierkegaard da seguinte maneira. "A Protestant theologian who demonstrated the vital intensity possible in theological reflection in the nineteenth century stated: The exception explains the general and itself. And if one wants for a true exception, it reveals everything more clearly than does the general." SCHMITT, Carl. Political Theology. The University of Chicago Press. United States of America. 2005. p. 15.

${ }^{21}$ Para aprofundar este ponto, conferir o artigo Ausnahme, de M. Theunissen, em Historisches Wörterbuch der Philosophie (2004).

${ }^{22}$ Dizemos "distantes" porque o conceito de Ereignis e de événement têm, certamente, diferenças significativas. Conferir: A Superação da Ontologia Fundamental de Heidegger pela Filosofia em Sistema de Alain Badiou (2011), de Norman R. Madarasz, p. 5-7.

${ }^{23}$ De fato, o próprio Schmitt utiliza essa mesma palavra: "The exception was something incommensurable to John Locke's doctrine of the constitutional state and the rationalist eighteenth century." (grifo nosso) SCHMITT, Carl. Political Theology. The University of Chicago Press. United States of America. 2005. p. 13-14.

\begin{tabular}{|c|c|l|l|l|l|}
\hline intuitio & $\begin{array}{c}\text { ISSN } \\
1983-4012\end{array}$ & Porto Alegre & Vol.7- $\mathrm{N}^{\mathrm{o}} .1$ & $\begin{array}{c}\text { Junho } \\
2014\end{array}$ & p.79-102 \\
\hline
\end{tabular}


situação, como em Badiou, ou uma ordem jurídica dada, como em Schmitt. A ruptura manifesta-se com maior clareza no ato da decisão, que vai manifestar o corte fundamental entre o momento anterior à exceção/acontecimento e o momento posterior a ele $^{24}$. Portanto, a singularidade, enquanto abertura, é geralmente ininteligível para a linguagem imperante na normalidade.

Entretanto, eles não são só irreconhecíveis pelo sistema. Mais radicalmente, são também incognoscíveis por ele, dado que, em geral, extrapolam todo aparato de decodificação, entendido como o conjunto de regras, conceitos e significados que compõem o sistema e que está preparado para operar somente dentro das margens da normalidade. É assim que, contrariando os liberais, Schmitt descreve a exceção fundamentalmente como um excesso que, enquanto tal, não pode ser subsumido, pois desafia qualquer intento de codificação dentro de uma norma. Para funcionar, a norma pressupõe a situação de normalidade (die normale Situation) e é ela, precisamente, o que a exceção interrompe. A ordem jurídica, para Schmitt, não pode se referir direitamente à exceção, só pode descrevê-la com uma referência negativa, a saber, dizendo o que ela não é: não é a normalidade. A exceção é, justamente, o que representa um perigo para ela ${ }^{25}$. De forma similar, o acontecimento é descrito, por Badiou, como um fato que rompe abruptamente com a normalidade ${ }^{26}$, a tal ponto que "[se] existe um acontecimento, sua pertença à situação do seu sitio é não decidível desde o ponto de vista da situação mesma"27.

Por outro lado, Badiou, como Schmitt, também destaca que ao acontecimento só podemos nos referir negativamente ${ }^{28}$ : ao menos no plano ontológico, ele só é formalizável através da figura matemática do vazio. No mesmo sentido, o filósofo também afirma que o acontecimento é impossível de ser dito em relação ao saber atual ${ }^{29}$. Entendendo por saber atual a "petrificação burocrática de uma

\footnotetext{
${ }^{24}$ WRIGHT, Colin. Event or Exception: Disentangling Badiou from Schmitt, or, Towards a Politics of the Void. Em: Theory and Event 11.2. 2008. p. 4.

25 "The exception, which is not codified in the existing legal order, can at best be characterized as a case of extreme peril, a danger to the existence of the state, or the like." (grifo nosso) SCHMITT, Carl. Political Theology. The University of Chicago Press. United States of America. 2005. p. 6.

${ }^{26}$ Com efeito, assim o expõe Meillassoux no seu texto Histoire et évènement chez Alain Badiou (2008) «La nouveauté d'un événement se dit dans le fait qu'il interrompt le régime normal de la description et du savoir, qui repose toujours sur le classement du bien connu, et impose un autre type de démarche à qui admet que quelque chose, là, en ce lieu, jusque là innommé, s'est bel est bien passé. » (grifo nosso) MEILLASSOUX, Quentin. Histoire et événement chez Alain Badiou. Em: Intervention au séminaire «Marx au XXe siècle : l'esprit et la lettre ». 2 Février 2008. Paris.

${ }^{27}$ BADIOU, Alain. Being and Event. Translated by Oliver Feltham. Ed. Continuum. United States. 2005. p. 180. (tradução própria).

${ }^{28}$ Concretamente, Badiou aponta: "In other words, the negative aspect of the definition of eventual sites-to not be represented -prohibits us from speaking of a site 'in-itself'. A multiple is a site relative to the situation in which it is presented (counted as one). A multiple is a site solely in situ. In contrast, a natural situation, normalizing all of its terms, is definable intrinsically, and even if it becomes sub-situation (a sub-multiple) within a larger presentation, it conserves its character." BADIOU, Alain. Being and Event. Translated by Oliver Feltham. Ed. Continuum. United States. 2005. p. 176.

${ }^{29}$ De novo Meillassoux : «Un événement est toujours indécidable au regard du savoir, et peut donc toujours être annulé par celui qui ne croit qu'aux faits bruts : y a-t-il révolution politique, ou simple accumulation de désordres et de crimes ? Rencontre amoureuse, ou simple désir sexuel ? Nouveauté picturale, ou amas informe et imposture ? etc. » (grifo nosso) MEILLASSOUX, Quentin. Histoire et événement chez Alain Badiou. Em : Intervention au séminaire « Marx au XXe siècle : l'esprit et la lettre ». 2 Février 2008. Paris. p. 3.
}

\begin{tabular}{|c|c|l|l|l|l|}
\hline intuitio & $\begin{array}{c}\text { ISSN } \\
1983-4012\end{array}$ & Porto Alegre & Vol.7- $\mathbf{N}^{\circ} .1$ & $\begin{array}{c}\text { Junho } \\
2014\end{array}$ & p.79-102 \\
\hline
\end{tabular}


verdade acontecimental", uma petrificação que se transforma em um obstáculo para a emergência de novas verdades ${ }^{30}$. Resumindo: nem a exceção nem o acontecimento podem ser discerníveis apelando aos critérios da situação anterior, porque no momento preciso da singularidade estes critérios se tornam inúteis. Como veremos, só o ato decisionista da nominação, condição de possibilidade da ação, poderá dotar de entidade concreta esse incognoscível que se apresenta inesperadamente.

Ambos os autores assinalam que a singularidade gera tal pressão sobre a estrutura do estado de situação que faz com que a mesma se veja empurrada até seus próprios limites formais, fazendo-a colapsar precisamente ali - o "site", segundo o jargão de Badiou - por onde a verdade acontecimental entra em cena. Em outras palavras, exceção e acontecimento são os pontos de fuga dos sistemas, aquilo que mostra, contra Hegel, e junto a Gödel, a insuficiência radical da qual os mesmos estão condenados a padecer. No seu núcleo, representam essa falta essencial: a impossibilidade formal e substantiva de constituir uma totalidade fechada.

Decerto, é por isso que Badiou afirma que toda verdade é post-événementielle, pois a verdade é um processo que se abre justamente quando um determinado estado de situação chega a seu fim: é, como dizia Lacan, "um buraco no saber" (savoir). Assim mesmo, em Schmitt, a exceção também pode ser concebida como um "buraco", mas, em lugar de levar ao reino da verdade e dos múltiplos inconsistentes, é um buraco que conduz ao domínio puro do político, que é chamado de "nomos", e que permite ademais o ingresso da "vida real" na esfera jurídica. Precisamente, "[na] exceção, [diz Schmitt] o poder da vida real se infiltra entre a crosta de um mecanismo que [como o savoir em Badiou] se tem tornado letárgico pela repetição" ${ }^{31}$. Consequentemente, podemos dizer que o nomos de Schmitt é, em alguma medida, como a situação de Badiou: aquele espaço que se apresenta no aparecer no momento do acontecimento.

Nesse sentido, podemos dizer que as singularidades não são somente, e meramente, desestabilizadoras, senão que também são revolucionárias, dado que se levantam contra as normas, os sujeitos ou, para utilizar a linguagem de Badiou, os "corpos" previamente constituídos no estado de situação, como poderiam ser, por exemplo, a ordem jurídica, um paradigma de conhecimento ou a monarquia absoluta. De fato, é justamente por isso que, em ambos os sistemas de pensamento, com a emergência do novo, também ocorre dialeticamente a emergência da negação do novo, a qual buscará evitar, de todas as maneiras possíveis, que as consequências da exceção ou do acontecimento transformem a realidade tal como esta é no presente. Essa reação contra a alteridade, que se apresenta intempestivamente no estado de situação, descontinuando sua lógica de repetição, toma as formas concretas, como aprofundaremos mais adiante, de sujeito obscuro em Badiou e de ditador comissarial em Schmitt.

\footnotetext{
${ }^{30}$ BENSAIID, Daniel. Badiou ou le miracle de l'événement. Une version réduite du chapitre II, partie II, intitulé «Alain Badiou et le miracle de l'événement» dans l'ouvrage Résistances. Essai de taupologie générale Fayard, Paris. 2001. (tradução própria).

${ }^{31}$ SCHMITT, Carl. Political Theology. The University of Chicago Press. United States of America. 2005. p. 15. (tradução própria).
}

\begin{tabular}{|c|c|l|l|l|l|}
\hline intuitio & $\begin{array}{c}\text { ISSN } \\
1983-4012\end{array}$ & Porto Alegre & Vol.7- $\mathbf{N}^{\circ} .1$ & $\begin{array}{c}\text { Junho } \\
2014\end{array}$ & p.79-102 \\
\hline
\end{tabular}


Por outro lado, para os autores, a singularidade não emerge, em absoluto, de um processo de causalidade que se desenvolve no interior do sistema, além de que o sistema mesmo possa estar regido por essa lógica. Então, o esgotamento de um determinado estado de situação, que conduz ao momento da singularidade, não pode ser nem intrínseco nem necessário. Na realidade, o acontecimento e a exceção não podem ser derivados do estado de coisas anterior porque, eis outro ponto central de suas propostas, eles não fazem parte da situação mesma. Se bem que, em um sentido, eles pertencem à situação - na forma, como veremos, de possibilidade estrutural -, não estão, porém, incluídos dentro dela. Em ambos os casos, os autores assinalam que a exceção e o acontecimento se encontram fora do âmbito da normalidade, em algum espaço "extra-legal" 32 ou "meta-situacional", que é, por sua vez, a condição de possibilidade da norma e da situação.

Contudo, o importante a salientar aqui é que, na medida em que se movem fora da normalidade, tanto a exceção como o acontecimento não estão submetidos às determinações que regem esta. Na realidade, a exceção e o acontecimento têm um estatuto ainda mais categórico: são singularidades que não obedecem qualquer norma. Daí se entende porque a exceção e o acontecimento compartilham também o fato de serem ocorrências com um caráter contingente, aleatório, incalculável e, portanto, completamente imprevisível pela situação na qual se mostram ${ }^{33}$. Como consequência, sua intervenção na normalidade sempre será intempestiva: eles aparecem como pura contingência.

Mas, embora sejam essencialmente contingentes, há que apontar aqui que o acontecimento e a exceção podem, apesar disso, ser descritos também como tendo um caráter estrutural, por mais paradoxal que isso possa soar, na medida em que são uma possibilidade constitutiva da situação e da normalidade. Em Badiou, essa possibilidade é constatada formalmente na figura do vazio que pertence a todos os conjuntos e que, portanto, estará inevitavelmente presente em todos os estados de situação, só que em um estado inconsciente e reprimido até a irrupção do acontecimento. Do mesmo modo, a exceção, em Schmitt, é aquela contingência que é contemplada em toda Constituição como uma eventualidade irremediável e inescapável, frente a qual o soberano pode decidir suspendê-la, de modo a confrontar melhor à exceção. Daí que podemos dizer que exceção e acontecimento são ambos um elemento evanescente com respeito à normalidade, pois apesar de estarem fora da mesma, não obstante, pertencem a ela na forma de uma sempre presente possibilidade ${ }^{34}$.

Como é conhecido, para Schmitt, a norma, desde o ponto de vista jurídico, surge ex nihilo, posto que não há, como na proposta de Kelsen, uma Grundnorm, isto é, uma norma dentro do

\footnotetext{
${ }^{32}$ De fato, no caso de Schmitt, a própria palavra alemã para exceção (Ausnahme) faz referência a algo que está fora (Aus) do tomado (nahme).

${ }^{33}$ Conforme cita Wright, Badiou descreve o acontecimento, em Being and Event, como "[that which] is purely hazardous, and which cannot be inferred from the situation." WRIGHT, Colin. Event or Exception: Disentangling Badiou from Schmitt, or, Towards a Politics of the Void. In: Theory and Event 11.2. 2008. p. 3.

${ }^{34}$ Decerto, Schmitt, no primeiro parágrafo de Politische Theologie, usa a palavra alemã Grenzbegriff, que significa conceito limite, para descrever exceção. Como diz Agambem: "Estar-fuera y, sin embargo, pertenecer: esta es la estructura topológica del estado de excepción”. TORRANO, Andrea; LORIO, Natalia. Economía de la Violencia y figuras de la excepción. Soberanía y biopolítica. In: Revista Pléyade. Número 9. Enero - Junio 2012. p. 105.
}

\begin{tabular}{|c|c|l|l|l|l|}
\hline intuitio & $\begin{array}{c}\text { ISSN } \\
1983-4012\end{array}$ & Porto Alegre & Vol.7- $\mathbf{N}^{\circ} .1$ & $\begin{array}{c}\text { Junho } \\
2014\end{array}$ & p.79-102 \\
\hline
\end{tabular}


ordenamento jurídico que, como uma causa prima, fundamente a validade do mesmo. Na compreensão de Schmitt, o que dá origem a uma determinada ordem jurídica é a decisão sobre a exceção, o essencialmente político e metafísico dentro da jurisprudência ${ }^{35}$, que, enquanto tal, e como o próprio soberano, é "supra ius, contra ius et extra ius". Tanto a exceção quanto o acontecimento são causa sui. Desde o ponto de vista objetivo, sua existência não tem uma arché, pois a singularidade nunca poder ser o efeito de algo mais essencial ou fundamental, porque sua natureza consiste em se determinar a si mesma. Desde o ponto de vista subjetivo ${ }^{36}$, é a decisão de nominar o que dá à exceção

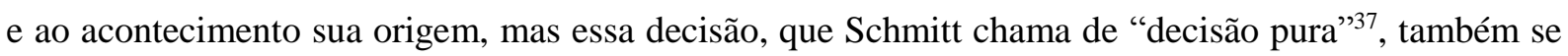
toma, desde o ponto de vista normativo, em um vazio, em um tipo de nada originário ${ }^{38}$.

$\mathrm{O}$ anterior explica também porque ambos os autores atribuem à singularidade um caráter milagroso. "A exceção [Ausnahmezustand] em jurisprudência [diz Schmitt] é análoga ao milagre em teologia"39. No entanto, há que dizer que, neste ponto, os filósofos mostram certas nuances. Efetivamente, enquanto em Schmitt a exceção mantém a remissão a uma instância transcendente, aquela onde se encontra o soberano, dado que justamente quer conservá-lo como evidência da origem teológica dos conceitos políticos modernos, Badiou, ao contrário, afasta-se explicitamente das conotações religiosas do termo, pois, para ele, e embora o acontecimento implique certamente uma transcendência dada pela emergência em forma quase que de revelação, de uma verdade que não se pode demonstrar ou provar empiricamente ${ }^{40}$, essa é sempre uma transcendência na imanência.

Menos problemático que o aspecto milagroso é o caráter "sublime" do qual são portadores, em nossa opinião, os conceitos de exceção e acontecimento. Justamente, como já dissemos, eles são,

\footnotetext{
${ }^{35}$ Dizemos que a decisão é metafísica porque o soberano tem que decidir o que vai ser concebido como ordem. Com efeito, "The "decision in its absolute purity" is not a decision as to what goods the social order shall embrace and encourage, but what shall count as order as such." NORRIS, Andrew. Sovereignty, Exception, and Norm. In: Journal of Law and Society, Vol. 34. 34. No 1. Democracy's Empire: Sovereignty, Law, and Violence (Mar., 2007), pp. 37-38.

${ }^{36}$ A exceção, em Schmitt, tem duas faces: uma face objetiva, "o estado excepcional em si mesmo" e outra subjetiva a declaração do "estado de exceção".

37 "The exception is that which cannot be subsumed; it defies general codification, but simultaneously reveals a specifically juristic element - the decision in absolute purity [Reinheit]." SCHMITT, Carl. Political Theology. The University of Chicago Press. United States of America. 2005. p. 13.

${ }^{38}$ Precisamente, como aponta Mika Ojakangas em "Carl Schmitt and the Sacred Origins of Law" (2009) "The event of decision is the ultimate origin and the absolute foundation of any legal order and political entity. In itself, however, the decision has no origin or foundation but springs out of a "normative nothingness and from a concrete disorder."' (grifo nosso) OJAKANGAS, Mika. Carl Schmitt and the Sacred Origins of Law. In: Telos 147 (Summer 2009): 34-54. p. 34. O próprio Schmitt, em La Dictadura, comentando a obra de Hobbes, assinala "La decisión que sirve de base a la ley, normativamente considerada, ha nacido de la nada. Por necesidad conceptual, es "dictada", pero la última consecuencia no se sacó hasta que no fue sacudido el racionalismo por de Maistre." SCHMITT, Carl. La Dictadura. Desde los comienzos del pensamiento moderno de la soberanía hasta la lucha de clases proletaria, Madrid: Ediciones de la Revista de Occidente, 1968. Traducción: José Díaz García. p. 28.

${ }^{39}$ SCHMITT, Carl. Political Theology. The University of Chicago Press. United States of America. 2005. p. 36. (tradução própria).

40 «Cette notion de vérité dépasse ce qui peut être prouvé ou démontré. Elle pose ses propres conditions de possibilité, autrement plus exigeantes que la simple cohérence, la correspondance ou la vérification des logiques ordinaires. » BENSAÏD, Daniel. Badiou ou le miracle de l'événement. Une version réduite du chapitre II, partie II, intitulé «Alain Badiou et le miracle de l'événement» dans l'ouvrage Résistances. Essai de taupologie générale, Fayard, Paris 2001.
}

\begin{tabular}{|c|c|l|l|l|l|}
\hline intuitio & $\begin{array}{c}\text { ISSN } \\
1983-4012\end{array}$ & Porto Alegre & Vol.7- N $^{\circ} .1$ & $\begin{array}{c}\text { Junho } \\
2014\end{array}$ & p.79-102 \\
\hline
\end{tabular}


como o objeto sublime de Burke e Kant, o inefável, é dizer, aquilo que é de uma grandeza incomensurável e ininteligível, que extrapola qualquer tentativa de compreensão racional, seja na forma de codificação legalista ou de formalização matemática. O sublime é a experiência estética da descontinuidade, tanto entre o sujeito e o mundo, quanto entre os diferentes mundos da realidade. É o sentimento que expressa, em um grau extático, a fatal irrupção do infinito/s no finito, da desordem na ordem e vice-versa ${ }^{41}$, causando, ao mesmo tempo, dor e prazer e despertando a consciência clara da própria subjetividade, enchendo-a de desejo (eros).

Precisamente, do mesmo modo que o sublime, a exceção e o acontecimento iluminam o sujeito, colocando-o nas vias da ação. Com efeito, assim como em Kant, o sublime, pelo fato de superar toda medida dos sentidos, põe a descoberto a atividade do sujeito transcendental na apreensão categorial do mundo fenomênico, em Schmitt, a exceção, em virtude de superar as margens jurídicas previstas na normalidade, revela a atividade subreptícia, os "filhos invisíveis", como ele mesmo diz, desse que é o sujeito político por excelência: o soberano transcendental. O mesmo sucede na proposta de Badiou ${ }^{42}$, só que, enquanto em Schmitt temos um chamado a um sujeito particular, já previamente constituído ou em processo de constituição, seja o ditador na ditadura comissarial ou o povo na ditadura soberana, em Badiou, o chamado visa à constituição de um novo sujeito, diferente do qual reina no estado de situação atual. Para expressar de outro modo: o que, em Schmitt, é um apelo ao sujeito para se mostrar, em Badiou é um apelo a se configurar, mas, em ambos os casos, o sujeito tem como tarefa fundamental a nominação do acontecimento/exceção.

Por outro lado, e seguindo Kant, o sublime pode ser o monstruoso, isso que é em extremo ameaçador, como o inimigo de Schmitt, e provocar assim negação, desprazer ou inclusive medo, mas também pode convocar um reencontro afetivo e amistoso com a alteridade que constitui o novo, provocando o prazer do entusiasmo e do engajamento, conforme vê Badiou inspirado no Maio de 68.

No início, dissemos que tanto Schmitt quanto Badiou caracterizam a exceção e o acontecimento em termos de ruptura. Mas, na realidade, seria parcial e, portanto, insuficiente, definilos somente como momentos meramente negativos que destroem a normalidade. Os autores, e eis outro ponto crucial que eles têm em comum, também os descrevem como sendo momentos positivos, no sentido de que eles têm também uma forte dimensão fundadora. Com efeito, conjuntamente com o aniquilamento da situação anterior, põe-se em marcha um processo de fundamentação de algo novo: a construção de outra normalidade. Schmitt o diz explicitamente quando assinala que é justamente a partir da exceção que se pode decidir o que vai ser tido como a situação normal daí em adiante. Toda constituição, que representa abstrata e juridicamente o ethos de uma ordem política concreta, é

41 "As the fluctuating boundary between order and disorder, the exception and the sovereign decision upon it (which are but two sides of the same thing) are themselves instances of either order nor disorder, but -as in Chesterton - more primordial, ecstatic mix of these opposites." NORRIS, Andrew. Sovereignty, Exception, and Norm. In: Journal of Law and Society, Vol. 34. 34. No 1. Democracy's Empire: Sovereignty, Law, and Violence (Mar., 2007), pp. 31-45-. p. 37.

${ }^{42}$ Novamente, recomendamos conferir o Capitulo 8 "Alain Badiou, or: From the Sublime to the Infinite" em The Romanticism of Contemporary Theory: Institutions, Aesthetics, Nihilism de Justin Clement.

\begin{tabular}{|l|c|l|l|l|l|}
\hline intuitio & $\begin{array}{c}\text { ISSN } \\
1983-4012\end{array}$ & Porto Alegre & Vol.7- $\mathrm{N}^{\mathrm{o}} .1$ & $\begin{array}{l}\text { Junho } \\
2014\end{array}$ & p.79-102 \\
\hline
\end{tabular}


produto, para Schmitt, de uma exceção ou, sendo mais preciso, do que ele chamará da política do extra-ordinário: o que é, por assim dizer, um tipo de "singularidade congelada". Badiou defende no mesmo sentido em relação ao acontecimento, uma vez que, ao trazer consigo uma nova verdade, o acontecimento gera uma lealdade e, portanto, um processo de subjetivação que dará lugar a um novo estado de situação, a uma nova ordem.

O anterior é crucial para entender as lógicas de transformação que operam no interior dos projetos dos autores. Com efeito, a exceção e o acontecimento são, justamente, as condições que habilitam a possibilidade da transformação dentro dos sistemas aos quais pertencem. Obviamente que para essa possibilidade se efetivar na realidade concreta devem se dar certas condições, tais como a nominação, a decisão (soberana ou não soberana) e o compromisso de um sujeito fiel, etc. que lhes permitam se desdobrar em suas verdadeiras conseqüências.

Em Schmitt, o estado de exceção deve ser suficientemente intenso para gerar uma via de reconstituição da comunidade política: a isso Schmitt chama de extraordinário. De forma similar, em Badiou, o acontecimento tem que ter tal magnitude que cause um estremecimento do estado de situação: a isso Badiou chama de singularité forte. Mas, se a exceção e o acontecimento não forem suficientemente fortes, a transformação, como veremos, será então uma transformação sem efeitos: um simples fato (fait), sem consequência real alguma, como o coloca a fenômeno-lógica de Badiou, ou uma exceção fraca, que terminará sendo sufocada pelo poder comissarial do soberano, como expõe Schmitt.

\section{Lógicas de transformação em Schmitt}

Na obra de Schmitt, sobretudo, no texto Die Diktatur (1921), encontramos que a comunidade política que, como veremos, é corporificada, segundo o modelo do autor, pela figura de soberano, pode se relacionar de duas formas com a possibilidade da transformação que conduz ao estado de exceção. Referimo-nos, em primeiro lugar, ao que Schmitt denomina de ditadura comissarial e, em segundo, a ditadura soberana. Enquanto a primeira tem como alvo fundamental eliminar a possibilidade da transformação, uma vez que é interpretada basicamente como uma ameaça que abre o estado de exceção; de modo contrário, a segunda abraça essa possibilidade permitindo à comunidade política uma nova constituição, tanto no sentido político quanto jurídico do termo. Muitas vezes, esta distinção que Schmitt faz tem sido esquecida em favor do primeiro tipo de ditadura, que é o arquétipo de ditadura conservadora. Todavia, aqui queremos salientar que, mais afim à proposta de Badiou, $o$ autor alemão também contempla a possibilidade de transformação ao assinalar que sempre o povo (das Volk), enquanto autêntico soberano, tem a opção de decidir mudar sua configuração presente e, por meio do chamado pouvoir constituant, plasmar democraticamente essa vontade nas instituições políticas e jurídicas.

\begin{tabular}{|c|c|l|l|l|l|}
\hline intuitio & $\begin{array}{c}\text { ISSN } \\
1983-4012\end{array}$ & Porto Alegre & Vol.7 $-\mathrm{N}^{\circ} .1$ & $\begin{array}{c}\text { Junho } \\
2014\end{array}$ & p.79-102 \\
\hline
\end{tabular}


Contudo, para efeito de poder compreender apropriadamente qual é a differentia especifica de cada tipo de ditadura e como se articulam, em cada uma, os conceitos de sujeito, exceção e transformação, tanto entre si como em relação às categorias ontológicas que propõe Badiou, é preciso abordá-las separadamente.

\section{a) A Ditadura Comissarial}

A figura de ditadura comissarial, diz Schmitt, provém da tradição republicana romana e implica, dito brevemente, na suspensão da ordem jurídica vigente durante o estado de exceção, tendo essa suspensão como objetivo primordial a proteção da comunidade política tal e como estava constituída antes da irrupção da exceção. Mais concretamente, o ditador comissarial tem como função básica a eliminação das ameaças, seja as que se apresentam na forma de uma revolta civil, de uma guerra ou de qualquer outra conjuntura especial desse estilo, que representa um declarado inimigo (inimicus) que pode ser externo ou interno. Dado o anterior, podemos dizer que durante a exceção ocorre o paradoxo de que o ditador comissarial pode, em nome da proteção da comunidade política, desrespeitar o mesmo corpo legal que justamente pretende salvaguardar. Transgredir para proteger: essa é, in nucce, a filosofia que sustenta sua figura.

É evidente que a suspensão da ordem legal tem como consequência que o sujeito encarregado de decidir dita suspensão terá, a partir desse momento, liberdades jurídicas para tomar todas as medidas que considere necessárias, incluindo a permissão transitória ${ }^{43}$ para violar direitos de terceiros. $\mathrm{O}$ alvo disso é enfrentar da forma mais efetiva possível a crise. Com efeito, Schmitt destaca em Die Diktatur que,

aqui [na situação de exceção] é tão grande o interesse por obter sucesso, que os obstáculos jurídicos que possam impedir a obtenção do sucesso podem deixar de ser levados em consideração, se houver lugar para isso. ${ }^{44}$

Daí, justamente, que o sujeito seja, desde o ponto de vista jurídico, um ditador. Mas, o ditador comissarial, assinala Schmitt, não tem nenhum conflito jurídico durante a excepcionalidade: tampouco rege a conflitos normais do tipo moral. Isso significa que o ditador é livre para escolher aqueles meios que, na situação de normalidade, iriam contra à lei ou à moral ${ }^{45}$. Além disso, estes tipos de ações

\footnotetext{
${ }^{43}$ Schmitt diz em relação a isso: "No es que se deroguen las leyes en que se apoyan esos derechos de terceros, sino solamente que en el caso concreto puede actuarse sin tomar en consideración los derechos" SCHMITT, Carl. La Dictadura. Desde los comienzos del pensamiento moderno de la soberanía hasta la lucha de clases proletaria, Madrid: Ediciones de la Revista de Occidente, 1968. p. 71.

${ }^{44}$ SCHMITT, Carl. La Dictadura. Desde los comienzos del pensamiento moderno de la soberanía hasta la lucha de clases proletaria. Traducción: José Díaz García. Madrid: Ediciones de la Revista de Occidente, 1968. p. 71. (Tradução própria).

${ }^{45}$ Com efeito, "There are absolutely no norms, customs, or laws that define or limit the possibilities open to him. For, according to Schmitt, it is the sovereign who first creates the norms put of which order arises." FRYE, E,
}

\begin{tabular}{|c|c|l|l|l|l|}
\hline intuitio & $\begin{array}{c}\text { ISSN } \\
1983-4012\end{array}$ & Porto Alegre & Vol.7- N $^{\circ} .1$ & $\begin{array}{c}\text { Junho } \\
2014\end{array}$ & p.79-102 \\
\hline
\end{tabular}


seriam, em algum sentido, obrigatórias, e eis a contrafase da sua liberdade, caso elas conduzissem à restauração do status quo ante, que é a razão de ser, como dissemos, do ditador comissarial e que, em certo sentido, dá uma orientação ética a seu agir em meio à emergência. É por isso, precisamente, que Schmitt aponta, lembrando Maquiavel, que neste tipo de ditadura a concreção do fim supremo eclipsa todos os meios para alcançá-lo. A eliminação do inimigo por parte do ditador merece que ele tenha a sua disposição todas as opções possíveis porque, depois de tudo, é a sobrevivência mesma da comunidade política, enquanto tal, o que está em jogo.

No entanto, durante a exceção, existem certas limitações jurídicas, embora, digamos assim, "não clássicas", que caem sobre os ombros do ditador comissarial. Em grandes linhas, elas estão dadas pelo fato de que ainda que a Constituição, e com ela todas as demais normas, possa ser suspensa em caso de emergência, suas estipulações sobre as funções e os parâmetros mínimos que o ditador comissarial tem que cumprir devem ser igualmente respeitadas ${ }^{46}$ : em outras palavras, como diz Schmitt, que seja suspensa não quer dizer que as normas ou a Constituição sejam revogadas ${ }^{47}$. Com efeito, na situação de exceção, a Constituição pode deixar de ter efeito, mas como é ela mesma, em primeiro lugar, a que habilita a possibilidade de sua própria suspensão e, portanto, as condições tanto pré quanto pós exceção, impõe sobre o ditador certas limitações que terão que perdurar até o final da crise, quando a vigência plena da constituição será restabelecida. Algumas dessas restrições são, por exemplo, a proibição de legislar, a estipulação de um limite de tempo para seu mandato e a subordinação ao autêntico soberano que é representado por uma autoridade superior.

Dadas essas limitações, está claro que, para Schmitt, o ditador comissarial, como se detalhará mais adiante, carece de atribuições propriamente soberanas, pois embora ele tenha poderes que, normalmente, seriam totalmente ilegais, além de imorais, ele, apesar disso, fica condicionado pelas previsões de uma Constituição, digamos assim, "entre parênteses”. Daí que Clinton Rossiter a tenha chamado, bastante pertinentemente, de "ditadura constitucional", mesmo quando a ruptura com a legalidade e a atribuição de poderes discricionais seja, ironicamente, o que caracteriza a ditadura.

Além desses conflitos jurídicos, o ditador comissarial também tem, na Filosofia de Schmitt, restrições de caráter político, que são tão ou mais importantes que as jurídicas. O que sucede é que, segundo nossa interpretação do autor, o ditador comissarial é um sujeito, para dizê-lo de algum modo, "duplamente" político, derivando-se dessa peculiar condição funções e diretrizes especificas.

Em primeiro lugar, o ditador comissarial é um sujeito político, senão um dos sujeitos políticos por excelência, porque, de acordo com o conceito de político, de Schmitt, que põe o acento na

Charles. Carl's Schmitt's Concept of the Political. In: The Journal of Politics [online] 15(4) pp.818-830. Nov. 1966. p. 828.

46 "Although he stands outside the normally valid legal system, he nevertheless belongs to it, for it is he who must decide whether the constitution needs to be suspended in its entirety." SCHMITT, Carl. Political Theology. The University of Chicago Press. United States of America. 2005. p. 7. (grifo nosso)

${ }^{47}$ SCHMITT, Carl. La Dictadura. Desde los comienzos del pensamiento moderno de la soberanía hasta la lucha de clases proletaria. Traducción: José Díaz García. Madrid: Ediciones de la Revista de Occidente, 1968. p. 71.

\begin{tabular}{|c|c|l|l|l|l|}
\hline intuitio & $\begin{array}{c}\text { ISSN } \\
1983-4012\end{array}$ & Porto Alegre & Vol.7- $\mathbf{N}^{\circ} .1$ & $\begin{array}{c}\text { Junho } \\
2014\end{array}$ & p.79-102 \\
\hline
\end{tabular}


distinção existencial amigo-inimigo (Freund-Feind $)^{48}$, ao ditador comissarial tem sido dada, no estado de exceção, a tarefa política por excelência: a fixação, a negação e, por último, a destruição do inimigo (inimicus). É por essa razão que a sua função se limita essencialmente a reprimir, podendo utilizar para isso todos os meios coercitivos que sejam necessários. Nesse sentido, podemos dizer que o ditador comissarial tem, fundamentalmente, atribuições do tipo executivas, e nenhuma função legislativa como tem o ditador soberano.

Em segundo lugar, o ditador comissarial é um sujeito político pela simples razão de que ele foi constituído pela comunidade política à qual pertence e, por conseguinte, à qual deve sua lealdade. Nesse sentido, a ditadura comissarial é uma forma de delegação. O ditador é assim um tipo de pars pro toto, dado que é uma pessoa pontual, que pensa e atua como se fosse o todo mesmo. De fato, é justamente por essa razão que ele tem que responder por seu agir diante de uma autoridade política já constituída, isto é, o verdadeiro soberano, que é a instância política superior por representar a comunidade política. Essa autoridade política é a que autoriza e a que designa ao ditador soberano, encarregando-lhe da tarefa específica de proteger a constituição da comunidade. Nesse ponto, há que esclarecer que com constituição não queremos nos referir à ordem legal, senão, seguindo Hegel, à identidade política da comunidade em questão. Com efeito, a suspensão da ordem legal é feita para se ter mais efetividade na preservação do ethos da comunidade, que é, como Schmitt empenha-se em demonstrar, o nomos $^{49}$ político que subjaz detrás de toda a legalidade e que a pressupõe para funcionar. Todo o edifício jurídico repousa sobre a base da normalidade política, de modo que quando esta se encontra perturbada, derrubam-se, conjuntamente a ela, as condições que permitem ao direito operar. Precisamente, nesse contexto, é que, afirma Schmitt:

A ação do ditador deve criar uma situação em que o direito possa ser realizado, pois cada norma jurídica pressupõe, como meio homogêneo, uma situação normal na qual tenha validade. Consequentemente, a ditadura é um problema da realidade concreta, sem deixar de ser um problema jurídico. ${ }^{50}$

\footnotetext{
48 Com "existencial" queremos dizer que a relação especificamente política envolve a possibilidade real da morte. Com efeito, "Los conceptos de amigo, enemigo y lucha adquieren su sentido real por el hecho de que están y se mantienen en conexión con la posibilidad real de matar físicamente.” SCHMITT, Carl. El concepto de lo político. Introdução de Rafael Agapito. 2 ed. Alianza Editorial. Madrid: 1991. p. 63.

49 "Para Schmitt, Nomos Basileu no es el gobierno de la ley, sino la expresión que detrás de la ley hay un nomos, un orden concreto. Para Schmitt, nomos es el orden del espacio, nomos significa establecimiento y espacio, y esto es previo al orden jurídico. Schmitt muestra que el concepto de orden es central para entender las cuestiones de lealtad, obediencia, disciplina y honor; pues los individuos no son vistos como individuos, como era el caso en Kant, sino como miembros de una institución, de órdenes particulares.” BENAVIDES, Samir. Excepción, Decisión y Derecho en Carl Schmitt. In: Argumentos 19(52), pp. 125-145, setiembre-diciembre, 2006. p. 140. Em Der Nomos der Erde (1950), o texto mais geopolítico de Schmitt, é aprofundado o conceito de nomos. Nesse contexto, tal conceito significa basicamente três condições de possibilidade para o governo da lei: a aquisição da terra, seu cultivo e a distribuição dos benefícios dela. A partir daí, o povo torna-se soberano sobre essa terra e a legitimidade para estabelecer as normas jurídicas que regerão a associação dos indivíduos.

${ }^{50}$ SCHMITT, Carl. La Dictadura. Desde los comienzos del pensamiento moderno de la soberanía hasta la lucha de clases proletaria. Tradução de José Díaz García. Madrid: Ediciones de la Revista de Occidente, 1968. p. 182. (Tradução própria).
}

\begin{tabular}{|c|c|l|l|l|l|}
\hline intuitio & $\begin{array}{c}\text { ISSN } \\
1983-4012\end{array}$ & Porto Alegre & Vol.7- N $^{\circ} .1$ & $\begin{array}{c}\text { Junho } \\
2014\end{array}$ & p.79-102 \\
\hline
\end{tabular}


Em poucas palavras, o ditador comissarial tem que pôr em parênteses uma "ordem abstrata", corporificada na Constituição, para restaurar uma "ordem concreta" e, na medida em que possibilita o sistema jurídico, mais fundamental. Essa ordem concreta é simplesmente aquele conjunto de valores substantivos que fundamentam o "estar-juntos" dos indivíduos, o espaço onde tem lugar a lealdade, a obediência, a disciplina e o engajamento espontâneo dos indivíduos, que, inclusive, pode levá-los até a morte em relação à comunidade. No momento da exceção, a comunidade, por meio da figura do ditador comissarial, afirma-se na sua forma de vida e seus próprios valores e, ao fazê-lo, está dizendo, ao mesmo tempo, não a todos os demais, especialmente àqueles que possam trazer consigo o inimigo, seja este interno ou externo. Nesse ponto, novamente, podemos perceber porque, para Schmitt, o ditador comissarial instancia à política em sua nudez e forma mais pura.

Uma vez suspensa a Constituição, o ditador comissarial não pode apelar à legalidade para validar seu agir. Na ausência da lei, o ditador vai recorrer à legitimidade que lhe dá a invocação dos valores abstratos de Nação ou de fé, mas que, no âmbito da comunidade política, tem significados e instituições concretas, compondo a ordem política particular desse Volk. ${ }^{51}$

\section{b) Ditadura soberana}

Além da ditadura comissarial, Schmitt também aponta que existe a figura do ditador soberano, cujas funções e alvos são de uma natureza essencialmente distintos da primeira. Primeiramente, o ditador soberano, de modo diferente do ditador comissarial, não tem um objetivo meramente conservador/restaurador. Sua tarefa é criadora, propriamente soberana: a saber, ele tem que ir além do estado de coisas existentes e fundar uma nova ordem, tanto política quanto jurídica, através da elaboração de uma nova constituição. Como vimos, o ditador comissarial podia suspender, temporariamente, a Constituição, visando a seu restabelecimento uma vez que o estado de emergência tivesse passado. Em contrapartida, a função do ditador soberano é muito mais radical: ele não vai restaurar a Constituição anterior porque tem como tarefa justamente romper com ela, anulá-la para sempre. Schmitt a explica da seguinte maneira:

A ditadura soberana vê agora, na ordenação total existente, a situação que quer eliminar mediante sua ação. Não suspende uma Constituição existente valendo-se de um direito fundamentado nela e, portanto, constitucional, senão que aspira a criar uma situação que possibilite uma Constituição, a qual considera como a Constituição verdadeira. Em consequência, não apela a uma Constituição existente, senão a uma Constituição que vai implantar. ${ }^{52}$

\footnotetext{
${ }^{51}$ BENAVIDES, Samir. Excepción, Decisión y Derecho en Carl Schmitt. In: Argumentos 19(52), pp. 125-145, setiembre-diciembre, 2006. p. 139.

52 SCHMITT, Carl. La Dictadura. Desde los comienzos del pensamiento moderno de la soberanía hasta la lucha de clases proletaria. Tradução de José Díaz García. Madrid: Ediciones de la Revista de Occidente, 1968. p. 182. (Tradução própria).
}

\begin{tabular}{|c|c|l|l|l|l|}
\hline intuitio & $\begin{array}{c}\text { ISSN } \\
1983-4012\end{array}$ & Porto Alegre & Vol.7- $\mathbf{N}^{\circ} .1$ & $\begin{array}{c}\text { Junho } \\
2014\end{array}$ & p.79-102 \\
\hline
\end{tabular}


Nesse sentido, podemos dizer que se o ditador comissarial era ilegal, pois precisamente tinha que violar a ordem jurídica para combater mais efetivamente o inimigo e, dessa forma, tentar salvá-la, o ditador soberano é, por definição, uma figura extra-legal, posto que, com ele, a legalidade anterior é declarada ultrapassada de modo a poder criar assim uma nova legalidade. O ditador soberano vai operar então em um momento de total vazio legal ou, mais exatamente, de "a-legalidade", pois se encontra justamente numa espécie de limbo entre, por um lado, um corpo legal que decidiu desativar e, por outro, a nova ordem jurídica a ser fundada também por ele mesmo.

Esse último aspecto é sumamente importante para compreender o ditador soberano, pois é precisamente essa função que outorga ao caráter ditador da ditadura soberana uma natureza fundamentalmente distinta a da ditadura comissarial. É claro que ambas são ditaduras na medida em que não estão vinculadas juridicamente, mas enquanto a ditadura comissarial o é por uma questão prática, de ser mais efetiva na hora de eliminar o inimigo, a ditadura soberana o é para poder decolar sem barreiras seu poder criador ou, sendo mais exato, o que Schmitt denomina, pegando o conceito de Sieyès, seu "poder constituinte" (pouvoir constituant). O ditador soberano não busca voltar a uma normalidade que foi alterada, senão que quer mais ambiciosamente estabelecer uma nova. Dessa maneira, se a ditadura comissarial se distinguia por ter poderes principalmente executivos, a ditadura soberana distingue-se por ter poderes basicamente legislativos.

Legalidade e ditadura são conceitos extremamente ligados, na teoria de Schmitt, pois do fato de que o soberano seja um ditador, também se deriva o fato de que não seria possível fundar uma nova ordem se o sujeito fundador tivesse condicionado pelas restrições que impõe à legalidade que se quer destruir: se assim fosse, cair-se-ia simplesmente em uma contradição nos termos, pois a nova ordem não seria, então, verdadeiramente nova, mas somente uma revisão parcial de um ordenamento já existente. Porém, é essa parcialidade que Schmitt quer evitar, dado que, para ele, o importante na ditadura soberana é a transformação integral ${ }^{53}$ da comunidade política: ab integro nascitur ordo. Daí que o soberano se torne necessariamente um ditador: sendo a condição de possibilidade de uma nova constituição, o exercício do poder constituinte tem que ser, como defendeu Hobbes, absoluto, isto é, livre de todas as limitações ou determinações externas.

Essa nova ordem legal não tem uma gênese identificável desde o ponto de vista jurídico. Sai do nada: é, como o assinala o próprio Schmitt, um "novo começo" 54 que não pode ser reconduzido a um momento normativo anterior. Aqui, Schmitt está se referindo especialmente contra Kelsen e seu purismo positivista, pois, em lugar de normas, para ele há primeiro decisão: a decisão de um soberano

53 Se a transformação radical é possível em Schmitt, o autor é consciente de que isso só acontece em determinadas condições. Nos demais casos de transformação, sempre encontramos alguma forma de continuidade. Com efeito, "However, Schmitt himself has acknowledged that a total break is conceivable only when the creation of a new constitution is accompanied by a change of the subject of the constituent power, as for example from the king to the people. In all the other cases, it remains a "constitutional minimum" that indicates a form of continuity." KALYVAS, Andreas. Democracy and the Politics of the Extraordinary. Max Weber, Carl Schmitt and Hannah Arendt. Ed. Cambridge University Press. United Kingdom. 2008. p. 118.

${ }^{54}$ Schmitt afirma expressamente: "The sovereign decision is the absolute beginning, and the beginning [...] is nothing else than a sovereign decision." citado em Sovereignty, Exception and Norm, de Norris (2008) p. 31.

\begin{tabular}{|c|c|l|l|l|l|}
\hline intuitio & $\begin{array}{c}\text { ISSN } \\
1983-4012\end{array}$ & Porto Alegre & Vol.7- N $^{\circ} 1$ & $\begin{array}{c}\text { Junho } \\
2014\end{array}$ & p.79-102 \\
\hline
\end{tabular}


que é absolutamente irredutível a alguma norma fundamental. Ainda mais, é o soberano quem definirá as normas fundamentais que terão que ser seguidas para criar as demais normas jurídicas. Por isso, Schmitt descreve ao poder constituinte (das begründende Gewalt) como um "conceito limite" (Grenzbegriff), igual à exceção. Nele, o jurídico e o político encontram-se para dar lugar a uma nova situação tanto legal quanto social. Precisamente, é o momento numinoso da decisão, enquanto poder constituinte, o que permite sair do niilismo que caracteriza o vazio jurídico que fica no momento de ruptura entre a antiga ordem legal e a futura nova Constituição.

Não obstante, quando é exatamente que entra em cena este tipo de ditadura na vida de uma comunidade política? Como vimos, na ditadura comissarial era a exceção. Seguindo a interpretação de Andreas Kalyvas ${ }^{55}$, podemos dizer que no caso da ditadura soberana é bastante distinto. Embora também seja uma exceção o que convoca o soberano a se apresentar, a mesma identifica-se melhor com um momento, digamos assim, milagroso, do que com uma emergência ou uma ameaça a ser eliminada (além de que também envolva violência), como era na ditadura comissarial. Com efeito, o tipo de exceção que desvela o ditador soberano, Schmitt a denomina de política do extraordinário. A mesma consiste na vontade explícita da comunidade política - ou, ao menos, de boa parte dela - de instaurar um novo arranjo jurídico e transformar, assim, todas as estruturas e instituições básicas da sociedade. Nesse sentido, podemos dizer que o extraordinário é uma exceção com uma intensidade radical, que, quando é efetiva, resulta na destruição do regime anterior e na substituição dele por um novo.

A política do extraordinário geralmente se efetiva, e daí seu caráter milagroso, com a atividade espontânea, criativa e cooperadora dos cidadãos, que se mobilizam como se fossem um único agente político, visando gerar uma reconfiguração da ordem de coisas existente. Em outras palavras, a política do extraordinário diz respeito, basicamente, a esses momentos fundacionais ou refundacionais, seja na forma de uma revolução, de uma declaração de independência, etc., que ocorrem, embora com pouca frequência, na história de um povo e que convocam a decidir sobre a forma da existência política desse povo. Esse chamado traduz-se concretamente no processo excepcional de criação das normas constitucionais (Verfassungsgesetz) da comunidade.

É importante aqui salientar a figura do povo, que é central na proposta de Schmitt. Precisamente, de acordo com sua teoria da legitimidade democrática, a partir da modernidade, o povo tornou-se o verdadeiro soberano da comunidade política e, por isso, representa o lócus mesmo do poder constituinte ${ }^{56}$. Na Idade Média, o soberano era o monarca, mímese de Deus, dotado de poderes extraordinários, em cuja figura se sintetizava a unidade da comunidade política. Mas, com o advento da modernidade e o instauração da democracia, esse caráter personalista e decisionista da soberania,

\footnotetext{
${ }^{55}$ Pontualmente, referimo-nos a Democracy and the Politics of the Extraordinary. Max Weber, Carl Schmitt and Hannah Arendt. Ed. Cambridge University Press. United Kingdom. 2008.

56 „Das Volk ist Träger der verfassunggebenden Gewalt und gibt sich selbs seine Verfassung“ Schmitt em "Verfassungslehre", citado em KALYVAS, Andreas. Democracy and the Politics of the Extraordinary. Max Weber, Carl Schmitt and Hannah Arendt. Cambridge University Press. United Kingdom. 2008. p. 99.
}

\begin{tabular}{|c|c|l|l|l|l|}
\hline intuitio & $\begin{array}{c}\text { ISSN } \\
1983-4012\end{array}$ & Porto Alegre & Vol.7- $\mathrm{N}^{\circ} .1$ & $\begin{array}{c}\text { Junho } \\
2014\end{array}$ & p.79-102 \\
\hline
\end{tabular}


como o assinala Schmitt ${ }^{57}$, perdeu-se no corpo fragmentado, impessoal e desorganizado da multidão, consagrando-se, assim, principalmente para o século XX, o que conhecemos como soberania popular.

Na soberania popular, a decisão personalista foi substituída, dessa forma, por aquilo, voltando de novo à Antiga Roma, Schmitt conceitualizou de "aclamação" (acclamatio). A "aclamação", parafraseando o autor alemão, é a forma mais elementar e natural de manifestação da vontade de um povo, que se efetiva com um "grito de aprovação ou negação" frente à tarefa crucial de decidir em que vai consistir sua própria existência política ${ }^{58}$ : é, em outras palavras, simplesmente um "sim" ou um "não", que pode ter, historicamente, diversas concretizações, como, por exemplo, a mobilização ou a opinião publica ${ }^{59}$. Temporariamente, o ditador soberano pode tomar a forma concreta de uma pessoa ou uma assembléia e poderá exercer um poder $a_{b s o l u t o}{ }^{60}$, mas, posteriormente, é o povo, através da "aclamação", o detentor último, a "sustância" mesma, do poder constituinte. Disso se deduz que o ditador soberano, depositário da vontade geral, é também uma forma de poder delegado, como também era o ditador comissarial.

Como foi possível observar, a política do extraordinário é um processo de reestruturação, de transformação radical da comunidade ${ }^{61}$ e o elemento que, para Schmitt, cristaliza política e juridicamente essa transformação é a Constituição (Verfassung). A Constituição tem como objetivo estabilizar o poder constituinte, protegê-lo de sua própria autodestruição, e, ao mesmo tempo, preservar a decisão soberana e, portanto, fundacional da comunidade relativa à definição do conteúdo e da forma da sua existência política, consagrando-a institucionalmente ${ }^{62}$. Por outro lado, a constituição também marca o trânsito de uma situação de indeterminação, de poder espontâneo e ilimitado de uma soberania popular sem forma e exaltada, o que no contratualismo corresponderia

${ }^{57}$ SCHMITT, Carl. Political Theology. Ed. The University of Chicago Press. United States of America. 2005. p. 48-49.

${ }^{58}$ Com o conceito de "existência política", Schmitt refere-se às decisões políticas "fundantes", como qual será a forma de representação política, os princípios da associação política e a modalidade de exercício do poder político.

59 "The natural form of the direct manifestation of the will of a people is a shout of approbation or the denial of the assembled mass, acclamation. In the large modern States, acclamation, the only natural and necessary manifestation of the people, has changed form. It expresses itself as public opinion. But the people in general can only say yes or not, to approve or to refuse, and its yes or no becomes particularly simple and elementary when it entails a fundamental decision on the ensemble of its proper existence". Schmitt, em Verfassungslehre, citado em KALYVAS, Andreas. Democracy and the Politics of the Extraordinary. Max Weber, Carl Schmitt and Hannah Arendt. Ed. Cambridge University Press. United Kingdom. 2008. p. 124-125.

60 "Los representantes extraordinarios, es decir, aquellos que ejercen de una manera inmediata el pouvoir constituant, pueden tener todo el pleno poder que les plazca, al contrario que los representantes ordinarios. Por ello, es preciso distinguir siempre el ejercicio del pouvoir constituant de su sustancia, pues, de no ser así, el pouvoir constituant sería constituido de nuevo en su representante extraordinario." SCHMITT, Carl. La Dictadura. Desde los comienzos del pensamiento moderno de la soberanía hasta la lucha de clases proletaria. Tradução de José Díaz García. Madrid: Ediciones de la Revista de Occidente, 1968. p. 192.

61 "Radical constitutional changes to be legitimate must come from the active citizens themselves." KALYVAS, Andreas. Democracy and the Politics of the Extraordinary. Max Weber, Carl Schmitt and Hannah Arendt. Cambridge University Press. United Kingdom. 2008. p. 143.

62 The constitution is a necessary and inescapable institutional and legal device to protect the constituent power from itself, from its fragile and ephemeral nature, by assisting it in exiting the extralegal zone and entering the realm of institutionalized political life. KALYVAS, Andreas. Democracy and the Politics of the Extraordinary. Max Weber, Carl Schmitt and Hannah Arendt. Cambridge University Press. United Kingdom. 2008. p. 135.

\begin{tabular}{|c|c|l|l|l|l|}
\hline intuitio & $\begin{array}{c}\text { ISSN } \\
1983-4012\end{array}$ & Porto Alegre & Vol.7- $\mathrm{N}^{\circ} .1$ & $\begin{array}{c}\text { Junho } \\
2014\end{array}$ & p.79-102 \\
\hline
\end{tabular}


com o "estado de natureza", a um momento onde essa soberania se dissolve, abdicando de suas atribuições quase onipotentes e autolimitando-se de modo a poder instituir-se legalmente. Antes da Constituição, estávamos no âmbito do extraordinário, com um soberano popular mobilizado e, portanto, plenamente visível, depois dela, o soberano domestica-se, subordinando-se ao conjunto de normas e regras que ele mesmo cria e legitima democraticamente. Em suma, com a Constituição, podemos dizer que a "besta" do soberano volta a dormir, deixando o caminho livre à legalidade e à normalidade.

Que o poder constituinte do povo se institua mediante a Constituição, não quer dizer, não obstante, que esse poder desapareça. Na realidade, o poder constituinte pode se retirar da esfera política, mas nunca pode nem se destruir nem concluir completamente sua instituição. Com efeito,

\begin{abstract}
A nação está sempre em um estado de natureza, diz uma famosa frase de Sieyès... [e o está] em relação a suas próprias formas constitucionais e com todos os funcionários que agem em seu nome. A nação está em um estado de natureza unilateralmente: só tem direitos, não obrigações; o constituant pouvoir não está sujeito a nada, no entanto, os pouvoirs constitués só têm obrigações e não direitos. ${ }^{63}$
\end{abstract}

Com isso, o que Schmitt está consagrando é a sempre presente possibilidade do povo de decidir se autotransformar em qualquer momento, instaurando-se "formas novas" tanto jurídicas quanto políticas ${ }^{64}$. Portanto, o estado de natureza não é superado, como nas teorias contratualistas clássicas, com a criação da sociedade política, isto é, do Estado. O filósofo alemão insere o estado de natureza, como uma possibilidade insuperável da comunidade, no centro mesmo da vida política, só que na forma de exceção ou do extraordinário.

\title{
3 A fenômeno-lógica de Badiou e as ditaduras
}

No seu Logique des Mondes (2006), Badiou assinala que embora o Ser seja imutável, sua aparição nos mundos é mutável e infinitamente variável, dado que as mesmas podem, diferentemente do domínio Ser, dar-se com diferentes níveis de intensidade. Ao aparecer dessas diferentes intensidades, Badiou o chama de existência e é, precisamente, a partir delas que o autor propõe, na sua fenômeno-lógica do aparecer, três tipos de mudanças acontecimentais, que veremos muito brevemente.

\footnotetext{
${ }^{63}$ SCHMITT, Carl. La Dictadura. Desde los comienzos del pensamiento moderno de la soberanía hasta la lucha de clases proletaria. Tradução de José Díaz García. Madrid: Ediciones de la Revista de Occidente, 1968. p. 189. (Tradução própria).

${ }^{64 "} \mathrm{La}$ voluntad puede ser oscura. Tiene incluso que serlo si el pouvoir constituant es realmente inconstituible. Esta consecuencia, que Sieyès ha expresado, deja ver ya la filosofía del siglo XIX, completamente opuesta al racionalismo, en la que Dios es el centro del universo, como un oscuro ser objetivo, del mismo modo que el pouvoir constituant informe, pero que produce siempre formas nuevas, es el centro de la vida estatal." SCHMITT, Carl. La Dictadura. Desde los comienzos del pensamiento moderno de la soberanía hasta la lucha de clases proletaria. Tradução de José Díaz García. Madrid: Ediciones de la Revista de Occidente, 1968. p. 190.
}

\begin{tabular}{|c|c|l|l|l|l|}
\hline intuitio & $\begin{array}{c}\text { ISSN } \\
1983-4012\end{array}$ & Porto Alegre & Vol.7- $\mathrm{N}^{\mathrm{o}} .1$ & $\begin{array}{c}\text { Junho } \\
2014\end{array}$ & p.79-102 \\
\hline
\end{tabular}


Em primeiro lugar, temos o que Badiou denomina "o fato" (le fait), que se caracteriza, principalmente, por ser um acontecimento cujas consequências no mundo onde se apresenta são praticamente nulas: quer dizer, é um acontecimento que não deixa quase nenhum rastro onde ocorre. Em segundo lugar, e no extremo oposto do fato, temos a singularidade forte (singularité forte), que é um acontecimento de intensidade máxima, ao ponto de que dá existência ao inexistente no lugar de sua aparição, e ao qual Badiou se refere como "o site" (le site). É este tipo de acontecimento o que acarreta consigo uma verdadeira mudança no estado de situação, geralmente em forma de revolução. Em terceiro lugar, Badiou assinala que existe também a singularidade fraca (singularité faible), a qual pode ser descrita como um tipo de ponto intermediário entre o mero fato e a singularidade forte. Um acontecimento que, em poucas palavras, deixa uma marca onde ocorre, mas que não atingiu a magnitude suficiente para provocar uma autêntica transformação do estado de situação.

$\mathrm{O}$ anterior remete, por sua vez, à concepção de sujeito de Badiou, pois, em sua filosofia, sujeito e acontecimento são, juntas, na verdade, duas expressões de um mesmo processo ${ }^{65}$. Com efeito, o acontecimento, enquanto singularidade forte, e sua subsequente nominação, desperta certamente novas formas de subjetividade, as quais podem se relacionar com o acontecimento, segundo Badiou, de três maneiras distintas.

Assim, temos, primeiramente, que o sujeito fiel (sujet fidèle) é um corpo subjetivado (corps subjectivé) que decide se organizar e tomar uma postura militante em relação a um acontecimento: principalmente, o que procura é construir um novo presente a partir da verdade que eclode nele. Ainda mais, em seu caminho de produzir esse porvir inédito, diz Badiou, o sujeito vai ter, adiante de si mesmo, várias alternativas entre as quais poderá escolher ${ }^{66}$. Essa escolha, que o autor chama de "des points", será decisiva para o desfecho final da tarefa e se decide, no interior da organização, simplesmente por um "sim" ou um "não".

Por outro lado, temos o sujeito reativo (le sujet reactif) que é, como o denomina Badiou, um "nouveauté réactionaire", e que, por sua própria natureza conservadora, nega-se a aceitar o novo, aquela alteridade radical que se apresenta no acontecimento, pois em algum sentido representa a inércia do antigo. Mas não é só isso: o sujeito reativo também pode produzir argumentos de resistência que falem a própria linguagem da novidade.

Por último, temos o sujeito obscuro (le sujet obscur) que vai ainda mais longe, pois não só nega, mas também se direciona para eliminar, desde a raiz, o novo presente que o acontecimento traz consigo através do sujeito fiel. Geralmente, para poder abolir a novidade, o sujeito obscuro invoca a pureza de um corpo transcendental, supostamente "pleno" e "a-histórico", como poderiam ser o

\footnotetext{
${ }^{65}$ BENSAIID, Daniel. Badiou ou le miracle de l'événement. Une version réduite du chapitre II, partie II, intitulé « Alain Badiou et le miracle de l'événement » dans l'ouvrage Résistances. Essai de taupologie générale, Fayard, Paris 2001.

${ }^{66}$ MEILLASSOUX, Quentin. Histoire et événement chez Alain Badiou. In : Intervention au séminaire « Marx au XXe siècle : l'esprit et la lettre ». 2 Février 2008. Paris. p. 9.
}

\begin{tabular}{|c|c|l|l|l|l|}
\hline intuitio & $\begin{array}{c}\text { ISSN } \\
1983-4012\end{array}$ & Porto Alegre & Vol.7- N $^{\circ} .1$ & $\begin{array}{c}\text { Junho } \\
2014\end{array}$ & p.79-102 \\
\hline
\end{tabular}


Estado, o Povo, a Raça ou Deus, para contrapô-lo à alegada inferioridade e impureza intrínseca da alteridade emergente, e, assim, acabar com suas aspirações transformadoras.

Esta tipologia fenômeno-lógica, que elabora Badiou, é perfeitamente aplicável à filosofia política de Schmitt. Nesse sentido, é preciso perguntar, então, que tipo de acontecimento e de sujeito, no modelo de Badiou, corresponde à exceção e aos sujeitos de ditador comissarial e soberano, tal como no esquema de Schmitt.

Segundo nossa interpretação, a natureza de exceção que tem que enfrentar o ditador comissarial se assemelha ao que, no sistema de Badiou, é o fato. Com efeito, a exceção, digamos assim, "comissarial" é um acontecimento de baixa intensidade, pois se o ditador comissarial for bem sucedido na sua função conservadora de restaurar a normalidade, então a exceção não será mais que uma mera alteração, contingente e temporária, da ordem de coisas, que terá um mínimo ou, em um extremo, nenhum impacto na vida política da comunidade como tal. Porém, também se poderia argumentar legitimamente que a exceção comissarial pode tomar, às vezes, a forma de singularidade fraca, dado que, por exemplo, uma revolta civil mal sucedida, pode deixar consequências políticas ou também jurídicas em uma sociedade. Mas, o que está fora de dúvida, segundo nosso ponto de vista, é que a exceção comissarial carece de força para se tornar uma transformação como a que gera a singularidade forte.

Por outro lado, é bastante claro que a figura de ditador comissarial é quase análoga à categoria de sujeito obscuro que descreve Badiou. Dado que lhe tem sido confiado o objetivo de proteger a constituição atual da comunidade, o ditador comissarial, como vimos, não economiza meios na hora de destruir ao inimigo. Nesse sentido, podemos dizer que o ditador comissarial, ao se propor proteger a Constituição atual, é fiel à verdade de um acontecimento já acontecido, que foi cristalizado justamente nessa Constituição, depositária da memória acontecimental. Ainda mais, o ditador comissarial executa sua tarefa alegando, a modo de escudo discursivo, ser a corporificação mesma de um corpo transcendental como é a Nação ou a Ordem, com os quais pretende extinguir a emergência da alteridade, que, por ser essencialmente anti-status quo e disruptiva, é sempre interpretada como uma ameaça, como inimiga.

Neste ponto, é notório que, em Schmitt, não há uma verdadeira reflexão sobre a alteridade. A mesma perde-se na lógica ambivalente que caracteriza toda sua filosofia. Referimo-nos à conhecida distinção amigo-inimigo ${ }^{67}$, homóloga da lógica inclusão-exclusão, que fundamenta, em seu sistema, a definição do político, e a partir da qual articula toda sua proposta. A diferença tem que ser negada, pois o "nós" sobre o qual se sustenta a coesão da comunidade, extrai dela, isto é, do "não-nós", sua

\footnotetext{
${ }^{67}$ De fato, é esta dialética truncada a que permite o jogo do político. Se a síntese tivesse lugar, então o confronto amigo-inimigo se dissolveria e, com isso, a possibilidade mesma do político. "Para Schmitt esta posibilidad de establecer quién es el enemigo y poder combatir contra él es lo que da entidad a un pueblo, de manera tal que, si renuncia o pierde esa facultad, entonces habrá dejado de constituir una unidad política." DOLORES, Marcos. Acerca de los conceptos de política y soberanía en Carl Schmitt y Thomas Hobbes. In: Foro interno (2004) 4. p. 54.
}

\begin{tabular}{|c|c|l|l|l|l|}
\hline intuitio & $\begin{array}{c}\text { ISSN } \\
1983-4012\end{array}$ & Porto Alegre & Vol.7- $\mathrm{N}^{\mathrm{o}} .1$ & $\begin{array}{c}\text { Junho } \\
2014\end{array}$ & p.79-102 \\
\hline
\end{tabular}


própria autoafirmação. E esse momento de negação absoluta do "outro" chega ao sumo de sua instanciação justamente com a declaração do estado de exceção.

Do mesmo modo que não há um tratamento da alteridade, tampouco há um esforço por distinguir tipos de exceção. No plano objetivo, todas elas se igualam em virtude de ter a semelhança negativa de representarem uma ameaça à ordem constituída. No plano subjetivo, elas também compartilham o fato de estarem sujeitas à vontade discricional do ditador, que pode igualá-las ao decidir nominá-las sob a figura abstrata de "exceção".

Contrariamente ao ditador comissarial, temos o ditador soberano que, em nossa opinião, teria uma forte correspondência com a categoria ontológica de sujeito fiel de Badiou. O que ocorre é que o acontecimento, que convoca o ditador soberano a aparecer, é de intensidade máxima: é, dito de outro modo, uma singularidade forte, uma exceção que tem superado a oposição natural do ditador comissarial e que, então, tem sido exitosa na transformação do estado de situação. A singularidade forte equivale assim, no pensamento de Schmitt, ao que ele chama de política do extraordinário, condição de possibilidade da transformação política e jurídica da comunidade. Do mesmo modo que o sujeito fiel, que jura lealdade à verdade que se mostra no acontecimento, o ditador soberano pretende, através de seu poder constituinte, fundar ou, se fosse o caso, refundar uma nova ordem política e legal: ou seja, busca, seguindo a linguagem de Badiou, criar um novo estado de situação, cuja estrutura, corporificada na nova constituição, permanecerá, a partir desse momento, leal a essa verdade acontecimental ou, para usar o vocabulário de Schmitt, ao "sucesso extraordinário" que lhe deu origem.

De igual modo, a política do extraordinário compartilha com a singularidade forte seu caráter milagroso, no sentido de que ambos convocam o começo de um processo de subjetivação: ou seja, ambos são da ordem do reencontro. Como vimos, para Schmitt, o ditador soberano é o povo mesmo, que, em um momento extraordinário, mobiliza-se e coopera com o sentido expresso de se reconstituir. Esse não é um sujeito instituído a priori como podia ser o ditador comissarial, senão um sujeito que, embora sempre presente, suas manifestações concretas vão se construindo com seu próprio devir. Este sujeito encontrará sua forma estável uma vez que decida sobre qual será sua constituição política, um processo que é levado a cabo, como assinalamos, mediante a "afirmação" e/ou "negação" que ocorre na "aclamação", a qual, vale dizer, relembra, com as nuances do caso, esses momentos decisivos que Badiou chama de "des points" e que também se resolvem com um simples "sim" ou um "não".

\section{Referências}

ATTILI, Antonella. La crítica decisionista de Carl Schmitt a la democracia liberal. In: Signos filosóficos, núm. 10, julio-diciembre, 2003, 129-148.

BADIOU, Alain. Infinite Thought: Truth and the Return of Philosophy. Ed. Continuum: London. 2004. BENAVIDES, Samir. Excepción, Decisión y Derecho en Carl Schmitt. In: Argumentos 19(52), pp. 125-145, setiembre-diciembre, 2006. Disponível em: http://redalyc.uaemex.mx/pdf/595/59505207.pdf.

\begin{tabular}{|c|c|l|l|l|l|}
\hline intuitio & $\begin{array}{c}\text { ISSN } \\
1983-4012\end{array}$ & Porto Alegre & Vol.7- N $^{\circ} 1$ & $\begin{array}{c}\text { Junho } \\
2014\end{array}$ & p.79-102 \\
\hline
\end{tabular}


BENSAIID, Daniel. Badiou ou le miracle de l'événement. Une version réduite du chapitre II, partie II, intitulé «Alain Badiou et le miracle de l'événement » dans l'ouvrage Résistances. Essai de taupologie générale, Fayard, Paris 2001. Disponível em: http://danielbensaid.org/Badiou-ou-le-miracle-de-l?lang=fr

BINETTI, María. El romanticismo de la angustia: de Kierkegaard a Heidegger y Lacan. In: La Mirada Kierkegaardiana $\mathrm{N}^{\circ} 0$. pp.10-21.

CLEMENS, Justin. The Romanticism of Contemporary Theory: Institutions, Aesthetics, Nihilism. Ed. Ashgate Publishing, Ltda., Jan 1, 2003 - Literary Collections.

DOLORES, Marcos. Acerca de los conceptos de política y soberanía en Carl Schmitt y Thomas Hobbes. In: Foro interno [online] 4, pp. 45-58, 2004. Disponível em: revistas.ucm.es/cps/15784576/articulos/FOIN0404110045A.PDF.

FERREIRÓS, José. Del neohumanismo al organicismo: Gauss, Cantor y la matemática pura. Universidad de Sevilla. 2003, págs. 165-184.

FRYE, E, Charles. Carl's Schmitt's Concept of the Political. In: The Journal of Politics [online] 15(4) pp.818830. Nov. 1966. p. 828.

GRIMSLEY, Ronald. Romantic Melancholy in Chateaubriand and Kierkegaard. Comparative Literature. Vol. 8, No. 3 (Summer, 1956), pp. 227-244. Disponível em: http://www.jstor.org/stable/1768290.

HONIG, Bonnie. The Miracle of Metaphor: Rethinking the State of Exception with RosenzIig and Schmitt. In: Diacritics, Vol. 37, No 2/3, Taking Exception to the Exception (Summer - Fall, 2007).

KALYVAS, Andreas. Democracy and the Politics of the Extraordinary. Max Iber, Carl Schmitt and Hannah Arendt. Cambridge University Press. United Kingdom. 2008.

LÖWY, Michael; SAYRE, Robert. Romanticism Against the Tide of Modernity. Ed. Duke University Press. Durham. London. 2001.

MADARASZ, Norman R. A Superação da Ontologia Fundamental de Heidegger pela Filosofia em Sistema de Alain Badiou. In: Revista Ensaios Filosóficos, Volume IV - outubro/2011. Brasil.

MEILLASSOUX, Quentin. Histoire et événement chez Alain Badiou. Em : Intervention au séminaire «Marx au XXe siècle : l'esprit et la lettre ». 2 Février 2008. Paris.

NORRIS, Andrew. Sovereignty, Exception, and Norm. In: Journal of Law and Society, Vol. 34. 34. N. 1. Democracy's Empire: Sovereignty, Law, and Violence (Mar., 2007), pp. 31-45-

ROSSELLO, Diego. Políticas de la excepción: Heidegger y Schmitt. Universidad de Buenos Aires. 14- 17 de Noviembre, 2001. Buenos Aires.

SAFRANSKI, Rüdiger. Romantismo: uma questão alemã. Tradução: Rita Rios. Ed. Estação Liberdade. 2009.

SCHMITT, Carl. El concepto de lo político. Introdução de Rafael Agapito 2 ed. Alianza Editorial. Madrid: 1991. SCHMITT, Carl. La Dictadura. Desde los comienzos del pensamiento moderno de la soberanía hasta la lucha de clases proletaria, Madrid: Ediciones de la Revista de Occidente, 1968. Traducción: José Díaz García.

SCHMITT, Carl. Political Theology. The University of Chicago Press. United States of America. 2005.

TACCETTA, Natalia. Violencia y derecho: Benjamin, Schmitt, Agamben y el estado de excepción. In: III Seminario Internacional. Políticas de la Memoria. Centro Cultural de la Memoria Haroldo Conti. Buenos Aires. TORRANO, Andrea; LORIO, Natalia. Economía de la Violencia y figuras de la excepción. Soberanía y biopolítica. In: Revista Pléyade. Número 9. Enero - Junio 2012.

WRIGHT, Colin. Event or Exception: Disentangling Badiou from Schmitt, or, Towards a Politics of the Void. In: Theory and Event 11.2. 2008.

Recebido em: 13/12/2013

Aprovado para publicação em: 27/05/2014

\begin{tabular}{|c|c|l|l|l|l|}
\hline intuitio & $\begin{array}{c}\text { ISSN } \\
1983-4012\end{array}$ & Porto Alegre & Vol.7- $\mathrm{N}^{\mathrm{o}} .1$ & $\begin{array}{c}\text { Junho } \\
2014\end{array}$ & p.79-102 \\
\hline
\end{tabular}

